\title{
GÊNERO E TECNOLOGIA NA ERRADICAÇÃO DA VARÍOLA ${ }^{1}$
}

\section{Jonatan Sacramento ${ }^{2}$}

Resumo: $\bigcirc$ objetivo desse texto é discutir a generificação das tecnologias de saúde pública, a agulha bifurcada e a vacina liofilizada, utilizadas na Campanha de Erradicação da Varíola. Ao mesmo tempo, lança-se mão da análise da trajetória profissional da enfermeira e educadora sanitária paulista, Geraldina Passeri, de modo a compreender como o gênero moldava as performances profissionais e o fazer burocrático e operacional de uma ação de saúde. $\bigcirc$ argumento sustentado ao longo do artigo é que mesmo os processos de gestão e execução de políticas de saúde, assim como das técnicas e tecnologias utilizadas, não estão isentos de significados de masculinidade e feminilidade.

Palavras-chave: gênero e saúde; tecnologias de saúde; erradicação da varíola.

\begin{abstract}
The aim of this text is to discuss the genderization of public health technologies, the bifurcated needle and the lyophilized vaccine, used in the Smallpox Eradication Campaign. At the same time, the analysis of the professional trajectory of the nurse and sanitary educator of São Paulo, Geraldina Passeri, is used to understand how how gender molded professional and bureaucratic performamnces and the operational health action. The argument discussed throughout the article is that even the health policy management and execution processes, as well as the techniques and technologies used, are not exempt from the meanings of masculinity and femininity.
\end{abstract}

Keywords: gender and health; health technologies; smallpox - eradication.

\section{Introdução}

A produção sobre gênero e saúde consolidada nas últimas décadas têm centrado suas análises nos modos como as práticas e discursos médicos recaem,

\footnotetext{
$1 \quad$ O presente artigo é parte das reflexões apresentadas em minha dissertação de mestrado, orientada pela Prof ${ }^{a}$ $\mathrm{Dr}^{\mathrm{a}}$ Heloísa Pontes, a quem sou mais do que grato. A pesquisa contou com o financiamento da FAPESP, mas as opiniões aqui emitidas são de minha inteira responsabilidade, não representado a opinião da agência. 
de diferentes formas, sobre os corpos masculinos e femininos (ROHDEN, 2001; LAQUEUR, 2001; MACHADO, 2005). Ao mesmo tempo em que contribuem para alargamento da nossa compreensão de que os processos de conhecimento e as práticas sociais são claramente marcadas pelos imaginários de gênero, esses estudos também nos oferecem o ferramental analítico para a compreensão de que essas mesmas práticas e os discursos médicos e científicos são construtores das ideias de gênero e, consequente, dos imaginários sobre as diferentes sexualidades

Nesse passo, um dos aspectos largamente criticados tem sido a noção de que as mulheres sejam natural ou biologicamente menos capazes. Isto é, as teorias feministas têm questionado os discursos que legitimam a inferioridade feminina.

Comungando com tal fortuna crítica, esse artigo pretende compreender como as tecnologias de saúde estão marcados pelos papéis de gênero, em especial, como as tecnologias de saúde pública utilizadas para a erradicação da varíola (anos 1960 e 1970) materializaram imaginários de masculinidade de feminilidade. Ou seja, o objetivo aqui é pensar como o gênero foi performado nas ações de erradicação da varíola, seja na concepção e desenvolvimentos das técnicas e tecnologias de saúde, quanto no papel desempenhado por homens e mulheres em tais atividades. $\bigcirc$ artigo foi desenvolvido a partir de pesquisa documental. Para tanto, lancei mão da análise dos documentos oficiais produzidos pelos responsáveis pelas atividades das Campanhas de Erradicação da Varíola no Brasil e no estado de São Paulo, depositados na Casa de Oswaldo Cruz/Fiocruz, no Rio de Janeiro, e no Centro de Memória do Museu de Saúde Pública Emílio Ribas, em São Paulo; do levantamento bibliográfico sobre a temática, de modo a lançar luz sobre a documentação arquivistica, e da análise de entrevistas e depoimentos com os e as participantes da Campanha, também depositados na Casa de Oswaldo Cruz/Fiocruz.

\section{A Campanha de Erradicação da Varíola}

A erradicação mundial da varíola aconteceu em 1977, após uma intensa campanha de vacinação em massa nos países da África, na Índia e no Brasil, coordenada pela Organização Mundial da Saúde (OMS) em cooperação com os governos locais. No Brasil, último país do continente americano a não ter erradicado a doença até aquele momento, a Campanha de Erradicação da Variola 
(CEV) teve início em 1966, e tinha como objetivo a vacinação de, no mínimo, $90 \%$ do contingente populacional do país. Primeira política de saúde em nível nacional, a Campanha alcançou seus objetivos no ano de 1971, recebendo o certificado internacional de país livre da doença em 1973.

Crucial para essa empreitada da erradicação, a primeira na história da humanidade, foram a agulha bifurcada, a vacina liofilizada (CHAGAS, 2008; GAZETA, 2006; HENDERSON, 2009; HOCHMAN, 2009b, 2011; VERANI; MARANHÃO e LANDER, 1993) e a estratégia da vigilância epidemiológica (SACRAMENTO, 2018). Sem tal conjunto de técnicas e saberes, o interrompimento da cadeia de transmissão da varíola, doença infectocontagiosa transmitida via contato físico ou exposição às secreções da pessoa infectada, não teria sido possível.

No entanto, se a literatura sobre o tema da erradicação não problematiza o processo de produção de tais tecnologias, uma análise mais detida dos processos sociais nos quais elas estavam imbricadas é capaz de revelar como as ferramentas utilizadas no combate à varíola materializaram relações de poder e de diferenciação mobilizados a partir das categorias de gênero e nacionalidade, mas não apenas. Nos próximos parágrafos, ao me voltar para os processos de criação desses dois instrumentos, pretendo deixar mais claro tal afirmação.

\section{Técnicas e tecnologias de saúde}

Como a literatura sobre o tema têm apontado ${ }^{3}$, dois foram os fatores técnicos imprescindiveis para o sucesso da erradicação da varíola no âmbito da CEV: a disponibilidade da vacina termoestável, a vacina liofilizada; e uma tecnologia de simples manejo, a agulha bifurcada. Junto a isso, como mostrei (SACRAMENTO, 2018), a instituição de um sistema de vigilância epidemiológica, foi o terceiro fator chave para o sucesso da Campanha. Assim, essa seção é dedicada à descrição dos dois primeiros fatores, pensando-os como tecnologias de poder, no sentido foucaultiano, que materializaram as relações envolvidas no processo de erradicação da varíola.

3 Chagas, 2008; Gazeta, 2001, 2006; Henderson, 2009; Hochman, 2009b e 2011; Verani; Maranhão; Lander, 1993. 


\section{A vacina liofilizada}

Se a invenção da vacina contra a variola é antiga, datando do século XVIII, a prática da variolização é ainda mais. Ao menos no Oriente, tem-se registro de seu uso já na Antiguidade. No entanto, se os esforços de Edward Jenner (Reino Unido, 1749-1823), pai da vacina antivariólica, lograram efeito na proteção das pessoas, a técnica de vacinação braço a braço sofreria alterações ao longo do tempo e, principalmente, com o advento da microbiologia, o desenvolvimento de uma vacina que já não dependia da prática da inoculação, mas antes, era produzida a partir da cepa viral desenvolvida no vitelo ou, ainda, encubada em ovos, foi uma invenção revolucionária (MOULIN, 1996, 1996a; FENNER, 1996). O passo seguinte seria sanar a fragilidade da vacina diante dos climas quentes dos trópicos ou das regiões mais quentes do globo.

Somente em 1919, Wurtz e Camus, pesquisadores franceses, desenvolveram um método melhorado de secar materiais biológicos. Partindo da lógica do ciclo hidrológico, onde a água passa do estado líquido para o sólido a partir de processos de solidificação a baixas temperaturas, a técnica de liofilização de Wurtz e Camus solidificava a vacina existente à época. Assim, ainda durante a primeira Guerra, foi produzida a primeira vacina liofilizada a partir da evasão a vácuo. ${ }^{4}$

Esta vacina, quando transportada da França para a Costa do Marfim, mostrava uma taxa de $85 \%$ a $100 \%$ de aproveitamento pós descongelamento (OMS, 1988). Nesse período, o fornecimento de vacina seca pelo Instituto Pasteur aos países de colonização francesa chegou a 12 milhões de doses anuais, número que se manteve até o ano de $1966 .{ }^{5}$

Em 1948, durante a primeira Assembleia Mundial de Saúde da OMS, Fred Soper, então diretor da Organização Pan-Americana de Saúde (OPAS), propôs que o United States National Institute of Health investisse no aperfeiçoamento da técnica de fabricação dessa vacina em parceria com Michigan Department of Health, que detinha a expertise de trabalho com vacinas glicerinadas, de modo a

4 A liofilização da vacina antivariólica feita por Camus e Wurt em 1919, mas também já testada por André Fasquelle (1867-1937), se dava pela secagem do material vacinal através do processo de centrifugação a vácuo.

5 A França manteve colônias no continente africano até a segunda metade do século XX. Nelas, mas não apenas, nesse mesmo século, foram instaladas filiais do Instituto Pasteur, importante órgão de pesquisa científica na área da biologia e na produção de vacinas, e responsável pela fabricação da vacina antivariólica na metrópole e nas colônias. Nesses laboratórios, a França produzia a vacina antivariólica que usava na profilaxia das colônias, tanto nos membros franceses, como nos africanos (cf. DEDET, 2000) 
fabricar, em larga escala, as vacinas a serem usadas nos trópicos. Em 1953, o Peru foi o primeiro país a produzir, em escala industrial, a vacina termoestável criada a partir do melhoramento da técnica de Wurtz e Camus pela OMS.

No entanto, diante do alto crescimento da demanda de vacinas termoestáveis, novas técnicas se fizeram necessárias para o desenvolvimento de uma vacina que fosse ainda mais potente para ser utilizada em climas quentes. Em 1951, L. H. Collier (1921-2011), então estudante de graduação no Lister Institute, Reino Unido, usando a técnica dos aparelhos de secagem por centrifugação, e ainda adicionando peptona, uma mistura de aminoácidos e polipeptídios oriundos da ação de uma enzima proteolítica, para preservar o vírus vacinal, conseguiu obter uma vacina termoestável mais eficaz e apta a ser produzida em escala industrial (COLLIER, 1998). Comparada com as vacinas anteriores, a de Collier mostrou $100 \%$ de eficácia após 64 semanas de armazenamento entre $37^{\circ}$ e $45^{\circ}$. Ela era preparada com linfa de ovelhas e usava do phenol como componente antibactericida. No laboratório onde trabalhava, no Lister Institute em Hertfordshire, Inglaterra, Collier contava com uma assistente recém-saída da escola e, segundo ele, sem nenhuma experiência em laboratório (COLLIER, 1998).

Em 1954, Collier desenvolveu uma técnica de secagem da vacina a partir da solidificação da mesma em seus próprios tubos, selando-os após o processo. Os testes posteriores mostraram que a vacina poderia ser conservada por 8 semanas em temperaturas de $37^{\circ}$ e que, ainda assim, guardaria uma eficácia de $100 \%$ em sua utilização. Também, quando testada no tipo de método a ser usado na vacinação, se aplicação intradérmica ou multipuntura, a última técnica se mostrou mais eficaz, razão que levou a OMS a adotar tal procedimento para a vacinação de erradicação da varíola. A partir de então, a Organização passa a utilizar o método de Collier na padronização da produção das vacinas que seriam usadas na campanha de combate à varíola.

O advento da vacina liofilizada, capaz de resistir às oscilações térmicas advindas do transporte para regiões mais quentes, principalmente diante da falta de uma cadeia de frio ${ }^{6}$, não disponivel à época, mostrou-se mais eficaz em formar "a pega"" a partir

$6 \quad$ Cadeia de frio é nome que se dá, hoje e à época, aos instrumentos capazes de manter refrigeradas as vacinas e outros componentes utilizados em atividades de profilaxia.

7 "Pega" é o nome que se dá à cicatriz vacinal decorrente da vacinação antivariólica quando exitosa. Mais do que o atestado vacinal, à época da CEV, o corpo de profissionais de saúde usava a existência ou não da cicatriz vacinal, a pega, 
da técnica de multipuntura - pressão múltipla sobre o braço de quem era vacinado, de modo a formar uma pequena escarificação por onde entrava a vacina. Para tanto, foi necessário também o desenvolvimento de uma nova tecnologia que pudesse ser, ao mesmo tempo, eficaz quanto à multipultura e fácil de se manusear. A agulha bifurcada surgiu nesse contexto.

Figura 1. A agulha bifurcada

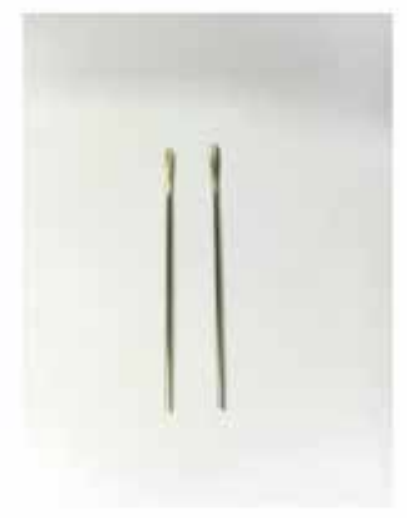

Imagem do autor (2018)

A história da técnica ligada à administração da vacina antivariólica reside não apenas no tipo de profilaxia escolhida, se vacinação ou variolização, como também, no próprio desenvolvimento dessas profilaxias ${ }^{8}$. Na prática da variolização, por exemplo, se fazia uso de um pequeno canudo para soprar, nas narinas de quem se queria imunizar, o pó das crostas das pústulas de pus da varíola. Na vacinação braço a braço, ou naquela realizada por Edward Jenner ${ }^{9}$, o instrumento utilizado pelo vacinador era uma agulha que, molhada na pústula de pus ou no vírus produzido no vitelo, era inserida na superfície da pele de quem seria vacinado.

Diferente das agulhas que atualmente são utilizadas nos processos de vacinação - instrumentos finos e ocos como um canudo, por onde passam as substâncias que serão injetadas no vacinado -, a vacina da varíola não obedece a esse procedimento

como prova e para saber se a vacinação tinha surtido efeito em determinado indivíduo. Atualmente, aqueles que foram vacinados com a vacina BCG (Bacilo de Calmette-Guérin, contra a tuberculose) também possuem uma cicatriz vacinal parecida com a pega da varíola.

8 Cf. Baxby, 2002 e 2003; Collier, 1998; Fenner, 1996; Moulin, 1996b; OMS, 1988.

9 Edward Jenner (Inglaterra, 1749-1823) foi um médico e naturalista inglês e descobridor da vacina antivariólica. 
de administração. Como não se injeta o líquido vacinal no paciente, o que lhe causaria problemas graves de saúde que poderiam levar à morte ${ }^{10}$, a agulha utilizada para a vacinação antivariólica deve conseguir, ao mesmo tempo, perfurar a camada de pele e ser capaz de depositar a quantidade de vacina necessária para que ocorra a imunização e não cause a doença no paciente.

Nesse sentido, algumas práticas e modos de ministrar a vacina foram promovidos ou proibidos ao redor do mundo com o avanço dos esforços de vacinação e da própria tecnologia da vacina. Na Índia, por exemplo, mesmo no início das ações da CEV no país, as autoridades sanitárias recomendavam que a puntura fosse feita em dois lugares diferentes, para que a vacina tivesse efeito garantido (BAXBY, 2002 e 2003). Com o advento da vacina liofilizada, várias ferramentas para a sua administração apareceram a partir da década de 1960, muitas delas parecidas entre si, variando apenas de acordo com a técnica de vacinação que se queria utilizar. As mudanças na bacteriologia e a necessidade de maior esterilização dos instrumentos de vacinação forçaram à adaptação aos novos padrões de higiene. Assim, duas das técnicas utilizadas nas campanhas de erradicação passaram a ser o injetor a pressão, para campanhas de massa que aconteciam em um único local, e a agulha bifurcada, inventada em 1961 por Benjamin A. Rubin".

A agulha bifurcada consiste num instrumento do tamanho de uma agulha comum, tendo uma de suas extremidades achatadas e, nesse mesmo local, possui dois "dentes", como um garfo, capaz de reter em sua circunferência a quantidade de substância necessária para a vacinação. Como apontam Baxby (2003) e os depoimentos de Quadros (2005), Amaral (2001) e Silveira (2005), ela é uma tecnologia simples, fácil de ser manuseada e, por isso, revolucionou o processo de vacinação antivariólica. Além disso, diferente das outras agulhas, a bifurcada podia ser esterilizada e reutilizada.

Ovacinador diluía a vacina liofilizada numa solução líquida de glicerina e mergulhava a ponta bifurcada da agulha nesse soro, para que se formasse uma pequena bolha de líquido vacinal entre os dentes do objeto. Com uma das mãos, o vacinador segurava o braço do vacinado e com a outra, apoiando o pulso sobre o lugar a ser picado e $10 \quad$ No caso da vacina antivariólica, como se trata de um vírus atenuado, o líquido vacinal é inserido numa fresta intradérmica do paciente que se quer vacinar, e não em sua corrente sanguínea.

11 Benjamin A. Rubin (EUA, 1917-2010) foi um médico estadunidense, doutor em Microbiologia pela Yale University e inventor da agulha bifurcada. 
mantendo a agulha em posição horizontal, a pressionava seguidamente sobre o braço de modo a fazer um pequeno ferimento sobre a pele. Após a vacinação, o vacinador deveria colocar a agulha em um recipiente separado para que, no final do dia, fossem realizados os procedimentos de esterilização, visando a reutilização no dia seguinte. $\bigcirc$ restante da vacina, que havia sido diluída para ser aplicada naquele dia, deveria ser descartado, pois não teria eficácia no dia seguinte.

\section{Generificando coisas - gênero, tecnologias e produção de conhecimentos}

Que o conhecimento não é um empreendimento neutro e livre de valores dos pesquisadores e pesquisadoras que o produz não é novidade para as ciências sociais (LOWY, 2003). Como inúmeros estudos têm mostrado, as circunstâncias políticas, geográficas e intelectuais onde o pesquisador está localizado influem no modo como ele concebe e constrói sua teoria (LOWY, 2006; LATOUR, 2011). No entanto, se as dimensões de classe e de nacionalidade, ou a localização na geopolítica internacional, são mais perceptiveis nos estudos sobre a produção do conhecimento científico, a dimensão de gênero é muitas vezes negligenciada ou relegada aos estudos que mais diretamente abordam a produção intelectual sobre a reprodução humana e a sexualidade (ROHDEN, 2001; LAQUEUR, 2001; MACHADO, 2005). Não desconsiderando a importância desses estudos para o conjunto da crítica feminista da ciência, é preciso levar em conta que masculinidade e feminilidade também se materializam na produção de outros conhecimentos que não os da matriz biológica reprodutiva ou filosófica e social. Ilana Lowy, por exemplo, têm mostrado como o imaginário das relações de gênero constitui o discurso científico inclusive naquilo que é entendido como universalidade e objetividade.

Segundo a autora (LOWY, 2000), a universalidade da ciência existe antes pela circulação dos conhecimentos e não por uma natureza universal a priori. Ou seja, na medida em que uma classe de especialistas se consolida ao redor do mundo, há também a necessidade das explicações teóricas ultrapassarem as fronteiras nacionais. Assim, ao alargar o alcance geográfico das explicações sobre os fenômenos naturais, a natureza passa a ser construída como algo partilhado universalmente. No entanto, menos que um relativismo científico, a ênfase da autora é na contingencialidade e historicidade do conhecimento produzidos pelas instituições científicas. Nessa perspectiva, os conhecimentos são situados na medida em que estão inscritos em 
redes e ações sociais localizadas tanto disciplinarmente, como contextualmente e, por isso mesmo, pautados sobre escolhas não aleatórias.

Nessa mesma direção, Evelyn Fox Keller mostra como, historicamente, a concepção de ciência foi construída ligada à ideia de masculinidade e como o feminino foi paulatinamente afastado do domínio do que era considerado científico e dos sistemas de produção de conhecimento (KELLER, 1985). Nessa empreitada, além da divisão explícita entre cultura e ciência de um lado, e natureza e sentimento, de outro, onde masculino e feminino foram divididos e alocadas em cada um desses polos, o objetivo de uma ciência feminista, pautada no olhar de gênero, seria o de não apenas compreender o papel das mulheres na história da ciência ou o modo como as ciências constroem as categorias de masculino e feminino, mas fundamentalmente, abordar a influência do gênero na construção histórica dos significados da ciência (KELLER, 2006; LOPES, 2006).

É esse exercício que se pretende desenvolver neste artigo. Ao analisar os processos de generificação da agulha bifurcada e da vacina liofilizada, no momento de sua criação, bem como nas relações cotidianas em que elas foram utilizadas, a vacina liofilizada e a agulha bifurcada, cada qual a sua maneira, corporificaram relações sociais que, em maior ou menor grau, eram perpassadas por noções de masculinidade e feminilidade e que diziam respeito não apenas a quem as criou, mas, também, ao contexto da produção científica e social de sua criação.

No caso em questão, ao analisarmos os documentos e depoimentos sobre o contexto de criação e utilização dessas duas ferramentas, eles apontam para a ausência de mulheres nos processos de produção e desenvolvimento dessas tecnologias. No entanto, os polos masculinos e femininos de organização de conhecimento não estão ausentes. A assistente de Collier, "que não tinha experiência em laboratório" e sequer foi nomeada por ele, a falta de médicas na equipe brasileira da erradicação da variola e a predominância das mulheres em ocupações como as de enfermeiras e educadoras, refletem um sistema social baseado numa (entre muitas) hierarquia de gênero que confere ao masculino um peso diferente do feminino, moldando a gramática dessas relações sociais, da produção de conhecimento e da distribuição nos postos de trabalho e de poder.

Assim, a medicina, mas não apenas, opera uma lógica de dois polos que estrutura 
a experiência do fazer da disciplina em masculina ou feminina. Nessa lógica, o polo masculino está ligado ao próprio exercício da medicina, principalmente nas especialidades ditas mais complexas (como as cirurgias e as neurociências) e também ao âmbito mais "científico" (como a genética e oncologia). Do outro lado, no polo feminino, encontram-se as áreas tidas como mais "práticas" ou vinculadas aos cuidados cotidianos, como a medicina da família/comunitária, centrada no cuidado, e a gerontologia ou a pediatria. Menos que uma generalização visando classificar papéis e práticas sociais em situações estanques, tal observação, feita a partir de um tipo ideal weberiano, permite um raciocínio claro do argumento que aqui se pretende desenvolver.

Assim, no polo masculino, localizam-se as grandes ações de saúde pública, como as campanhas de saneamento ou, no caso, as de erradicação. Como aponta Susan Sontag (SONTAG, 2007), o uso de metáforas para se falar de doenças ou de atitudes preventivas a elas, é recorrente em nosso imaginário. O mesmo se deu na Campanha de Erradicação da Varíola (CEV), muitas vezes descritas, nos livros e artigos, mas também nos depoimentos de seus participantes, como uma guerra a ser vencida contra um inimigo - a doença.

A guerra, que em muitas sociedades é uma atividade masculina por excelência, mesmo quando admite a participação de mulheres nos contingentes de batalha, é organizada em torno de uma retórica onde prevalecem a força, a coragem, a agressividade, a frieza e a estratégia, características essas tidas como masculinas.

No caso das campanhas de saúde, visando o saneamento dos sertões, a erradicação da febre amarela, da malária e da pólio, metáforas como "combater", "vencer o inimigo", "lutar contra a doença", são recorrentes nos discursos dos órgãos oficiais. Com a erradicação da varíola não foi diferente. Segundo um dos médicos que participaram da Campanha no Brasil, “(...) não é uma questão de doença. É uma questão de estratégia de guerra, não é? Quando você parte para uma erradicação, você tem que ter na cabeça uma logística e estratégia, não é?" (Depoimento de 2001). Ou seja, a CEV operava usando toda uma estratégica logística de guerra, focando o controle e a vigilância. Quer dizer, uma ação estratégica, logicamente formulada e com objetivos claros: vacinar o maior número do contingente populacional e erradicar (vencer) a variola.

Assim, a retórica da vigilância epidemiológica, técnica central para a garantia 
efetiva das ações de erradicação, foi construída através de um conjunto de saberes matemáticos, biológicos, mas também, do imaginário social onde os atributos legados ao gênero masculino foram mobilizados na produção de tais sistemas. Conceitos como os de notificação e bloqueio, ou mesmo a distinção entre controle, eliminação e erradicação, fazem não apenas uma alusão à guerra, como também, a pressupostos de gênero.

No léxico da epidemiologia, controlar uma doença implica em transformar o quadro epidemiológico em um nível em que ela não cause alarme e também impeça o risco de uma nova epidemia. Já a eliminação é um controle mais aguçado, visando garantir a eliminação total da doença, ainda que o agente causador da mesma continue a existir. Por sua vez, a erradicação pressupõe não apenas a eliminação da doença, como de seu agente patológico - seu extermínio. No caso específico da varíola, em que a presença do virus é inseparável da manifestação da doença, ou seja, é impossivel ter o vírus e não ter a doença, a possibilidade de erradicação via vacinação era viável pois o vírus se propagava apenas através de seres humanos e não possuía outro reservatório natural.

Depois de uma convivência "pacífica" entre a vacina e a doença por quase duzentos anos, a sentença definitiva contra a doença foi dada na década de 1960, em razão da criação do programa mundial de erradicação da varíola. A partir desse momento, o objetivo não era mais o controle ou a eliminação da doença, mas seu completo extermínio. Isso só foi possivel graças à adoção de uma estratégia de atuação de massa, como as campanhas de vacinação e as ações centradas em notificação e bloqueio. Uma estratégia de guerra.

Assim, como uma guerra não se faz apenas com estratégias, mas, sobretudo, com armas, a erradicação da varíola, além das estratégias da vigilância epidemiológica, só foi exitosa por contar com outras duas ferramentas: a agulha bifurcada e a vacina liofilizada. Na lógica do engendramento/generificação das coisas (CHABAUDRYCHTER e GARDEY, 2004), ambas as tecnologias estão marcadas por significados históricos, localmente contextualizados, materializando diferentes sentidos de masculinidades e feminilidades. Nesse sentido, não só pessoas, mas técnicas e ferramentas também carregam marcas de gênero em seus processos de produção, reprodução e transformação do mundo.

A agulha bifurcada, por exemplo, quando lida nessa chave, permite pensar questões relativas ao gênero, à erradicação da varíola e ao modo como a sociedade, à 
época, organizava as relações entre masculino e feminino.

Criada em 1961, a agulha bifurcada nasceu a partir de uma antiga ferramenta ligada às profissões tidas como mais femininas ${ }^{12}$. No entanto, enquanto ferramenta, a própria agulha não sofreu alterações significativas em sua forma. De concepção simples, uma haste cilindrica e fina feita de metal, o uso de tal instrumento como ferramenta em procedimentos profiláticos data da época de Edward Jenner, descobridor da vacina, e das primeiras tentativas de vacinação, nos idos de 1790. Ou seja, a agulha, instrumento da costura, atividade masculina em sua concepção, mas feminizada com o passar do tempo, manteve um caráter ambíguo no que se refere às marcas de gênero.

No caso do Brasil, na estratégia epidemiológica da CEV, a notificação consistia em comunicar às autoridades sanitárias dos centros de saúde municipais que, por sua vez, informavam às Campanhas de Erradicação da Variola estaduais e estas, por fim, à CEV nacional, todos os casos suspeitos de variola numa determinada região e dentro de um determinado período de tempo - semanal. De posse dos dados, as CEVs estaduais faziam a visita para confirmar ou não, via diagnóstico laboratorial, os casos notificados. Confirmados os casos de varíola, a CEV então iniciava as atividades de bloqueio vacinal.

bloqueio consistia na demarcação epidemiológica de um determinado surto visando interferir na sua transmissão e, assim, controlá-lo. Nesse sentido, o bloqueio era feito a partir da vigilância de duas gerações de casos, para um período de quarentena, sendo efetuada a vacinação de bloqueio nas áreas próximas ao caso notificado, onde a extensão territorial se modificava dependendo da origem do surto, se urbano ou rural, e do tamanho da cidade, se grande, média ou pequena (VERANI; MARANHÃO e LAENDER, 1993).

Havia também a estratégia da notificação cruzada, que consistia em acionar a vigilância epidemiológica da varíla em outras áreas que, por algum motivo, tivessem ligação com o caso notificado em uma determinada localidade, devido à circulação espacial do doente ou de seus contatos. Ou seja, a vigilância epidemiológica da variola pressupunha uma rede de inteligência de informação que permitia a identificação de

12 O processo de feminização da profissão de costura aconteceu no século XIX, quando a Revolução Industrial introduziu mudanças (maquinário) que resultaram na desqualificação da atividade e na feminização do métier. No mesmo período, a costura começava a ser ensinada nas escolas, menos como uma profissão e mais como uma tentativa de formação moral das meninas da época (Zylberg-Hocquard, 2004). Assim, o processo de feminização da profissão levou um saber adquirido e aperfeiçoado como era (é) o da costura, para o espectro das "atividades femininas por natureza". Sobre os processos de feminização das profissões e/ou de sua desqualificação via alterações tecnológicas, conferir, por exemplo, Cynthia Cockburn, 1998. 
todas as manifestações do "inimigo" e, a partir de determinadas estratégias, a atuação do "exército" da CEV era feita para prevenir, conter e erradicar a doença.

Usada principalmente na atividade da cirurgia, no momento da sutura pósoperatória, mas também na atividade profilática via vacinas injetáveis, a agulha, na medicina, transita entre instrumento utilizado por ocupações majoritariamente femininas e aquelas onde predominam o masculino, ainda que nem a enfermagem ou a medicina sejam domínio exclusivo de um único gênero.

Nos procedimentos operatórios, por exemplo, realizados em sua maioria por médicos, ela é um instrumento masculino. Na prática profilática, no cotidiano dos hospitais e centros de saúde, a atividade de vacinação é feita por enfermeiras e enfermeiros, mas cujo corpo profissional é ocupado majoritariamente por mulheres. Nas atividades de sutura mais simples, dos cuidados cotidianos, diferentes das cirurgias de maior complexidade, é também a enfermeira quem realiza tais tarefas.

No caso da agulha utilizada na vacinação antivariólica, seja nos tempos de Jenner, no final do século XVIII, ou da inovação da agulha bifurcada, ela ocupava o polo masculino da atividade da profilaxia. A prova disso é que a vacinação antivariólica foi ministrada por médicos e, até meados do século $X X$, a profissão da medicina era exercida majoritariamente por homens no Brasil (GUEDES, 2008; MOTT, 2005). Em relação à Campanha de Erradicação da Variola no país, a equipe de vacinadores era composta por homens. As mulheres integrantes da CEV eram responsáveis pela educação em saúde, pela enfermagem e pelos trabalhos administrativos. A ação de vacinar era delegada aos vacinadores, contratados exclusivamente para isso.

Tanto antes como atualmente, ainda que a agulha ocupe um lugar ambiguo no que diz respeito ao gênero, seja na sutura ou na profilaxia/aplicação, ela parece operar na lógica do cuidado e que, por sua vez, está alocado no polo feminino das atividades do trabalho. Se, no caso da sutura, a agulha permite a junção de duas ou mais partes e, através disso, a cicatrização do corpo, no caso da agulha bifurcada, em razão do vácuo entre os dois dentes do instrumento, ela permite o depósito da quantidade de vacina necessária para a profilaxia de êxito. Assim como na prática da regeneração via cicatrização proporcionada pela sutura, a multipuntura com a agulha bifurcada carregando a quantidade exata de vacina, possibilita a proteção necessária contra a varíla. 
A vacina liofilizada de Collier, por sua vez, traz em sua concepção um episódio particular no que diz respeito à relação entre gênero e autoridade científica. Segundo o cientista, assim que se instalou no Lister Institute, em Chelsea (Reino Unido), "Me atribuíram um laboratório no prédio principal, uma técnica júnior (uma jovem recémsaída da escola e sem nenhuma experiência em laboratório), e uma pequena cabana que abrigava um congelador experimental ${ }^{13}$ ". Para Collier, a presença de uma assistente que nunca havia estado antes em um laboratório (fato comum, poderíamos pensar, a todo profissional em começo de carreira) teria sido um dos desafios enfrentados por ele no desenvolvimento de uma vacina termoestável eficaz, justamente por não poder contar, segundo seu relato, com uma assistente que dominasse a dinâmica laboratorial.

Menos que uma curiosidade de sua trajetória, a forma como o autor narra em seu artigo a chegada ao laboratório do Lister Institute ajuda a contextualizar as condições de produção de seu trabalho à época. No decorrer do texto, com o desenvolvimento da narrativa sobre os procedimentos e etapas do desenvolvimento da vacina, a assistente sem nome de Collier desaparece de seu relato. Não como Boyle, e sua convicta crença no papel negativo da mulher para o bom andamento da prática científica (POTTER, 2001), a omissão de Collier sobre o papel desempenhado por sua assistente no desenvolvimento da vacina liofilizada talvez se deva mais a um jogo de ego, de tomar a si como o único responsável pelo desenvolvimento de uma inovação tecnológica, do que à partilha das mesmas crenças com o físico inglês. Contudo, o ponto a reter é a invisibilidade das mulheres no desenvolvimento da vacina liofilizada e, também, na própria erradicação da variola.

Nos documentos e depoimentos produzidos pelos atores da Campanha no Brasil, as mulheres aparecem apenas nos relatórios dos serviços de enfermagem e educação sanitária da CEV São Paulo, em âmbito regional. Nas narrativas sobre a CEV nacional e sobre os esforços mundiais da erradicação da varíola, como mostram os depoimentos dos membros da equipe brasileira que, posteriormente, atuaram na erradicação na Índia e na África, não há menção às médicas, enfermeiras ou às outras profissionais da $\mathrm{CEV}$, mesmo que elas tenham estado presentes no processo de erradicação.

A ausência de mulheres na Campanha de Erradicação da Variola, menos que

$13 \quad$ No original "I was allotted a laboratory in the main building, a junior technician (a young lady straight from school with no laboratory experience), and a little hut that housed an experimental freeze drier." (Collier, 1998: 343, tradução minha). 
uma excepcionalidade, reflete as dinâmicas das relações de gênero e da produção de conhecimento da época. No Brasil, na década de 1970, dentro do grupo reduzido de $2,18 \%$ da população com curso superior, apenas $25,6 \%$ desse total eram mulheres (GUEDES, 2008). Do total de egressos por curso naquela mesma década, as mulheres representavam $11 \%$ dos diplomas de Medicina e $93 \%$ dos diplomados em Enfermagem (GUEDES, 2008). Nesse sentido, seria previsivel que um empreendimento que demandasse mão-de-obra qualificada refletisse a situação do cenário educacional da época. No entanto, como tenho mostrado (Sacramento, 2018), a equação entre formação e atuação profissional não segue a mesma lógica do sistema educacional, menos ainda quando consideramos o quesito prestígio social (PONTES, 2006; CORREA, 2003).

Além de formação específica, outros dois componentes apareciam como requisitos não explícitos para a atuação na erradicação da varíola: o fato de ser recémformado e o pertencimento a uma rede de influência profissional. Menos que negar o componente técnico da formação desses profissionais para atuarem na erradicação da variola, o que se quer é demonstrar como outros fatores também influenciaram na escolha desses profissionais para participarem da CEV.

Como mostram os depoimentos consultados (AMARAL, 2001; QUADROS, 2005; SILVEIRA, 2005), situação de recém-egresso da universidade representava a possibilidade de contratação de jovens entusiastas com o desenvolvimento da profissão e com disponibilidade para a circulação territorial que o trabalho de erradicação da varíla exigia. Seja em forma de campanha de massa ou no modelo de vigilância epidemiológica, o trânsito dos profissionais da CEV era recorrente e muitas vezes acontecia em situações adversas. Por outro lado, a situação de egresso também significava que ele não estava envolvido em nenhuma outra atividade profissional, podendo assumir o regime de dedicação exclusiva oferecido pela CEV.

O elemento de novidade e entusiasmo é narrado por dois médicos da CEV (FIOCRUZ, 2001; 2005) quando explicitam que, para ambos, a escolha pela saúde pública tinha sido uma dimensão política, um componente a mais na formação técnica do médico, e que diferenciava o sanitarista daqueles que optaram por outras áreas. Assim, ambos alinham em seus raciocínios a trajetória de seus colegas sanitaristas apontando que o componente político para a formação na saúde pública era essencial, 
caso contrário, o médico acabaria por se tornar um mero burocrata (FIOCRUZ, 2001). Além disso, continuam, o sanitarismo brasileiro seria ímpar em sua formação, pois seus professores, médicos sanitaristas renomados, foram eminentes sanitaristas ligados, em maior ou menor grau, aos quadros e à ideologia do Partido Comunista.

No depoimento de um outro médico (FIOCRUZ, 2005), que escolheu a saúde pública como um meio de fazer política no cotidiano da prática profissional, ao permitir o envolvimento com as ditas "doenças dos pobres" - doenças infectocontagiosas e parasitárias -, foi essa mesma necessidade de atuação política via saúde pública que - levou ao Rio de Janeiro para fazer o curso de Saúde Pública na Escola Nacional. Lá, foi orientado pelo professor Ernani Braga a ter uma vivência profissional na área de saúde pública antes de entrar num curso de especialização. Assim, foi encaminhado à Fundação SESP (Serviço Especial de Saúde Pública), contratado por ela e enviado para trabalhar na Amazônia brasileira.

Mais tarde, sua atuação na Fundação SESP Ihe renderia um convite para participar da CEV no estado do Rio Grande do Sul. No caso do primeiro médico (FIOCRUZ, 2001), a participação na CEV permitiu-lhe atuar na erradicação da variola na Índia e na Etiópia. Ou seja, na trajetória de ambos, estão alinhadas, num mesmo patamar, a formação profissional, a disposição política e temporal em participar de um empreendimento que demandava tempo e dedicação, e uma rede de contatos profissionais. Tudo isso, somado, permitiu a integração desses profissionais nas campanhas de erradicação da varíola em nível nacional e internacional.

No caso das mulheres parece haver, ao menos, dois agravantes. Se existia um primeiro constrangimento em relação à ascensão ao ensino superior, depois de formadas, os desafios de gênero passavam a ser da ordem do que se esperava das mulheres ativas no mercado formal. Assim, a situação de jovem recém-formada e disponivel aos moldes da CEV era pouco frequente às médicas da época. A equação família e trabalho, com o acúmulo de papéis (profissional e dona de casa/mãe), não é exclusiva apenas de uma parcela da população. Nesse sentido, mesmo que o peso da classe não se fizesse presente no cotidiano das mulheres médicas, que possuíam condições de delegar as atividades da casa para uma outra mulher (relação esta que não está isenta de conflitos e tensões de poder), ainda assim, o peso da dimensão de gênero não era aliviado. Sair de casa num empreendimento como o da CEV, que 
pressupunha constantes viagens para lugares longe do lar, não era visto com bons olhos ainda na sociedade daquela época.

Contudo, a predominância masculina nos processos da Campanha de Erradicação da Variola não significa que as mulheres estiveram ausentes dessas ações. Menos numerosas e em funções tais como as de enfermagem, administração e treinamento, sobretudo, as funcionárias da CEV existiram e tiveram atuação cabal para o bom andamento das ações implementadas pela Campanha. Na próxima seção, discorro a trajetória profissinal de uma das enfermeiras que atuaram na etapa paulista da Campanha, Geraldina Passeri, de modo a pensar o lugar que ocupavam essas mulheres no contexto das ações de estado da época. Recorrer a esse exemplo serve para demonstrar, como afirma Pontes, que a experiência das mulheres que atuaram no combate à varíola, quando entendidas no contexto social nos quais estavam inseridas, foi moldada por essas como "um destino para o qual não haviam sido preparadas" (PONTES, 2006, p. 98).

\section{As mulheres nas políticas de erradicação}

Geraldina Passeri foi enfermeira e assessora técnica da Campanha de Erradicação da Variola noestadodeSão Paulo. Emanálise dos relatórios mensais deatividades de Geraldina é possivel reconstruir em partes as dinâmicas cotidianas do trabalho de enfermagem da CEV São Paulojá no final das atividades da Campanha no estado e no Brasil.

Responsável pelos treinamentos dados às equipes de saúde que trabalhavam com a variola nos centros de saúde e das Diretorias Regionais de Saúde, em todo o estado de São Paulo, além da coleta e do tratamento dos dados epidemiológicos emitidos pelas Unidades de Vigilância Epidemiológica da capital e do interior, Geraldina constantemente apontava para as péssimas condições dos centros de saúde onde os espaços de formação aconteciam. Além disso, a falta de padronização dos procedimentos na coleta de informação sobre os casos suspeitos de varíola, necessário para as ações de vigilância epidemiológica, e com os cuidados em vacinação, por exemplo, eram apresentados como desafiadores para a enfermeira chefe, que tinha também como função a de treinar e orientar médicos, enfermeiros e outros profissionais de saúde nas questões relativas às estratégias da CEV. Profissionais esses que, nem sempre, estavam abertos à terem sua expertise confrontada por uma 
enfermeira de um serviço de saúde emergencial.

O papel de educação sanitária desempenhado pela enfermeira da CEV era o de formar as equipes de saúde regionais para o diagnóstico exato dos casos suspeitos de varíola, a coleta das informações e a aplicação de vacinas, bem como o de mobilizar ações de sensibilização para com a população público alvo da campanha sobre a importância da vacinação no combate à varíola. Se a doença já era uma velha conhecida de todos, a medida profilática via vacina parecia não ter a mesma intimidade com o público. Cabia à educadora sanitária então a elaboração de materiais educativos, assim como criar e lecionar cursos e atividades de modo a sensibilizar a população sobre o uso da vacina.

Recorrer à enfermeira e educadora como aquela que teria como função as tarefas de esclarecimento e conscientização não foi novidade da CEV. Antes da Campanha, a figura da profissional de educação sanitária já tinha sido bastião dos discursos de saúde pública, principalmente em São Paulo, na época da reforma sanitária de 1925 (ROCHA, 2005). Por possuírem formação pedagógica e um amplo alcance de influência, já que circulavam nas escolas e faziam parte do cotidiano de formação de inúmeras crianças, seus discursos reverberavam junto às familias desses escolares. Segundo Rocha, sendo uma profissão eminentemente feminina, a educadora sanitária colaborava não apenas para a difusão do discurso científico em saúde, mas também, no auxilio aos médicos e sanitaristas, os homens da ciência que esclarecia e curava (ROCHA, 2005, p. 100).

No entanto, se a atuação em educação sanitária aparece como que num plano secundário, o trabalho administrativo da enfermeira parece ocupar um lugar ambíguo. Ainda que não ocupasse nenhum cargo de alto escalão, as atividades desempenhadas por Geraldina Passeri mostram uma certa autonomia de atuação profissional por parte, ao menos, de seu grupo de enfermeiras lotadas na superintendência estadual da Campanha. Em São Paulo, cabia à Geraldina o treinamento de médicos, enfermeiras e vacinadores de todo o estado, além da supervisão das atividades dessas equipes. Junto a isso, o trato dos dados referentes aos casos notificados de variola pelas diretorias regionais de saúde, e que seriam enviados ao Ministério da Saúde, ou seja, a sistematização de um certo conhecimento técnico que lhe revestia de autoridade para 
exigir, como mostram alguns relatórios, maior autonomia na supervisão das equipes da CEV e na formulação de diretrizes para coleta e sistematização desses dados.

No entanto, é importante pontuar que o poder de atuação enquanto enfermeira chefe da Campanha em nivel estadual também tinha seus limites bem definidos. $\bigcirc$ exemplo mais claro é o fato de que a formação e a supervisão de mão de obra da Campanha se davam, prioritariamente, na figura dos vacinadores. Ou seja, numa escala hierárquica de atuação dos profissionais da Campanha, os vacinadores seriam a base inferior dessa pirâmide de ocupações, por serem, ao mesmo tempo, funcionários contratados temporariamente para as atividades da Campanha, não possuindo vínculos enquanto categoria com os outros profissionais da saúde pública, e mão de obra que não exigia alto nivel de escolaridade, e por serem eles próprios, segundo os documentos e a bibliografia disponivel, parte daquela população que deveria ser esclarecida pelo trabalho das educadoras sanitárias.

Como aponta Wajcman (1991 e 1998), as tecnologias estão moldadas a partir da lógica da divisão do trabalho, sendo assim, operam também na lógica da divisão sexual do trabalho. As enfermeiras e educadoras sanitárias, ainda que possuíssem certo grau de educação formal - no caso das enfermeiras, também o curso superior - tinham acesso restrito aos saberes biológicos dominados pelos médicos da Campanha. Por outro lado, a enfermeira chefe da Campanha em São Paulo, Geraldina Passeri, detinha um conhecimento técnico da formulação dos dados epidemiológicos sobre os casos de variola, além de estar revestida de um poder estatal que lhe permitia supervisar o trabalho de outros funcionários estatais - entre eles, as enfermeiras e os médicos das diretorias regionais de saúde.

Nessa dinâmica, parece que o poder estatal da enfermeira chefe é dependente tanto de sua qualificação como enfermeira, quanto do domínio das técnicas da epidemiologia. Assim, num quadro mais geral, o acesso à escolarização formal e à profissionalização parecia representar uma alavanca social para as mulheres no que diz respeito ao exercício de profissões qualificadas - já que a inserção do trabalho feminino no mercado formal e informal, principalmente, é bem anterior ao período aqui estudado. Nesse ínterim, ao mesmo tempo em que o domínio de técnicas do campo da saúde permitia alterar algumas dinâmicas de gênero, no tocante à divisão sexual do trabalho, para que um salto maior no quesito prestígio profissional fosse 
dado seria necessário o ingresso dessas mulheres nas cadeiras das faculdades de medicina - ainda que, a qualificação profissional sozinha não tenha sido garantia de acesso das mulheres aos postos chaves da CEV (SACRAMENTO, 2018).

A garantia do conhecimento técnico e do saber necessário para o manejo das ferramentas adequadas para as atividades preconizadas pela erradicação da varíola eram também elementos que garantiam a manutenção do prestígio de Geraldinajunto aos outros membros da Campanha. Nesse sentido, as tecnologias de saúde também têm de ser tomadas enquanto artefatos localizados temporalmente na história do pensamento científico, assim como os usos que delas foram feitas e as relações que tais ferramentas mobilizaram não apenas no que diz respeito às dinâmicas de gênero, mas aos significados dos prestígios sociais que mobilizaram.

\section{Conclusão}

Pensar a articulação entre gênero e saúde têm nos ajudado a compreender ainda mais o caráter social que os processos de saúde e doença possuem. Se a crítica no seio da saúde coletiva e das ciências humanas, por exemplo, têm evidenciado a limitação das interpretações biologizantes de tais processos, essa crítica, quando alinhavada sob a dimensão de gênero, permite compreender como esses mesmos múltiplos significados de enfermidade e saúde, mas não apenas, adquirem outros diferentes significados para homens e mulheres. No entanto, uma crítica às tecnologias de saúde que leve em consideração não apenas os aspectos políticos e econômicos desses artefatos, mas os considere como parte dessa dinâmica de polissemia de sentidos ainda é incomum.

$\bigcirc$ que esse artigo quis mostrar foi justamente o caráter generificado que as técnicas e tecnologias de saúde pública, notadamente aquelas envolvidas na erradicação da varíola, adquiriram. Menos que fetichiza-las e colocá-las sob o domínio de ferramentas opressoras que excluiam, de antemão, toda e qualquer atuação feminina, o argumento que quis desenvolver foi o de como essas tecnologias foram agenciadas de modo a materializarem diferentes significados de masculinidades e feminilidades a depender do contexto social na qual estavam localizadas.

Pensar as lógicas generificadas das técnicas e dos protocolos em saúde pode nos ajudar a melhor compreender seus usos e, consequentemente, a pensar em 
maneiras alternativas e mais inclusivas, no quesito gênero, do fazer cotidiano da saúde e suas ações.

Referências

AMARAL, C. Depoimento. Acervo de Depoimentos Orais Memória da Poliomielite. Rio de Janeiro, Fiocruz/Casa de Oswaldo Cruz/Departamento de Pesquisa/Departamento de Arquivo e Documentação, 2001.

BAXBY, D. Smallpox vaccination techniques; from knives and forks to needles and pins. Vaccine, vol. 20, issue 16, pp. 2140-2149, 2002.

Smallpox vaccination techniques 2: accessories and aftercare. Vaccine, vol. 21. issue, 13-14, pp. 1382-1390, 2003.

CHABAUD-RYCHTER, D.; GARDEY, D. L'Engendrement des choses. Des hommes, des femmes et des techniques. Éditions des archives contemporaines, 2004.

CHAGAS, D. C. Erradicando doenças: De projeto internacional ao sistema de vigilância epidemiológica - A erradicação da variola no Brasil (1900-1970). 2008. Dissertação (Mestrado em História das Ciências e da Saúde) - Casa de Oswaldo Cruz, Fundação Oswaldo Cruz, Rio de Janeiro, 2008.

COLLIER, L. An angel's trumpet Development of the heat stable smallpox vaccine. Interdisciplinary Science Reviews, 23:4, pp. 340-347, 1998.

CORREA, M. Antropólogas \& antropologia. Belo Horizonte: Editora UFMG, 2003.

GAZETA, A. A. B. A Campanha de Erradicação da Varíola no Brasil. Dissertação (Mestrado em Saúde Coletiva) - Universidade Federal do Rio de Janeiro, Rio de Janeiro, 2001.

Uma Contribuição à História do Combate à Varíola no Brasil: do Controle à Erradicação. 2006. Tese (Doutorado em História das Ciências e da Saúde) - Casa do Oswaldo Cruz, Fundação Oswaldo Cruz, Rio de Janeiro, 2006.

GUEDES, M. C. A presença feminina nos cursos universitários e nas pósgraduações: desconstruindo a idéia da universidade como espaço masculino. História, ciencias, saúde - Manguinhos, Rio de Janeiro, v. 15, supl. p. 117-132, 2008.

HENDERSON, D. A. Smallpox: the death of a disease : the inside story of eradicating a worldwide killer. Amherst, NY: Prometheus Books, 2009.

HOCHMAN, G. Priority, invisibility and eradication: the history of smallpox and the Brazilian Public Health agenda. Medical History, London, v.53, n.2, p.229-252, 2009 b. 
Vacinação, varíola e uma cultura da imunização no Brasil. Ciência e Saúde Coletiva, vol.16, n.2, pp. 375-386, 2011.

KELLER, E. F. Reflections on gender and science. New Haven; London: Yale university press, 1985.

Qual foi o impacto do feminismo na ciência? Cadernos Pagu, Campinas, n. 27, p. 13-34, 2006.

LAQUEUR, T. Inventando o sexo: corpo e gênero dos gregos a Freud. Rio de Janeiro: Relume Dumará, 2001.

LATOUR, B. Pasteur: guerre et paix des microbes; suivi de Irréductions. Paris: la Découverte, DL 2011.

LOPES, M. M. Sobre convenções em torno de argumentos de autoridade. Cadernos Pagu, Campinas, n. 27, p. 35-61, 2006.

LOWY, I. Universalidade da ciência e conhecimentos "situados". Cadernos Pagu, Campinas, n. 15, p. 15-38, 2000.

. Virus, mosquitos e modernidade: Ciência, política e febre amarela no Brasil. Rio de Janeiro: Editora da Fiocruz, 2006.

LOWY, M. As aventuras de Karl Marx contra o Barão de Munchhausen: marxismo e positivismo na sociologia do conhecimento. São Paulo: Cortez, 2003.

MACHADO, P. S. O sexo dos anjos: um olhar sobre a anatomia e a produção do sexo (como se fosse) natural. Cadernos Pagu, Campinas, n. 24, p. 249-281, jun. 2005.

MOTT, M. L. Gênero, medicina e filantropia: Maria Rennotte e as mulheres na construção da nação. Cadernos Pagu, Campinas, n. 24, p. 41-67, 2005.

MOULIN, A. (Org.). L'aventure de la vaccination. Paris: Fayard, 1996.

MOULIN, A. L'aventure humaine de la vaccination. In: L'aventure de la vaccination. Paris: Fayard, 1996a.

POTTER, E. Gender and Boyle's law of gases. Bloomington: Indiana university press, 2001.

PONTES, H. A paixão pelas formas. Novos Estudos CEBRAP, São Paulo, p. 87-105, 2006.

ROCHA, H. H. P. A educação sanitária como profissão feminina. Cadernos Pagu, Campinas, n. 24, p. 69-104, 2005.

QUADROS, C. Depoimento. Projeto Vacina Antivariólica. Fundação Oswaldo Cruz, Casa de Oswaldo Cruz, 2005. 
ROHDEN, F. Uma ciência da diferença: sexo e gênero na medicina da mulher. Rio de Janeiro: FIOCRUZ, 2001.

SACRAMENTO, J. Saberes, poderes e corporalidades: a biopolítica da erradicação da varíola no Brasil. 2018. Dissertação (Mestrado em Antropologia Social) - Unicamp, Campinas, 2018.

SILVEIRA, C. M. Depoimento. Projeto Vacina Antivariólica. Fundação Oswaldo Cruz, Casa de Oswaldo Cruz, 2005.

SONTAG, S. Doença como metáfora: AIDS e suas metáforas. São Paulo: Companhia de Bolso, 2007.

VERANI, J. F.; MARANHÃO, E.; LAENDER, F. Desenvolvimento dos sistemas de vigilância epidemiológica da varíola e da poliomelite: a transformação de conceitos em categorias operacionais. Cadernos de Saúde Pública, Rio de Janeiro, v. 9, n 1, pp. 28-38, 1993.

WAJCMAN, J. Feminism confronts technology. University Park: Pennsylvania State University Press, 1991. Pagu, Campinas, n. 10, 1998.

Tecnologia de produção: fazendo um trabalho de gênero. Cadernos

Recebido em fevereiro de 2018.

Aceito para publicação em maio de 2018. 